\title{
SOBRE UMA FOTOGRAFIA DE CAMILO PESSANHA
}

\author{
Paulo de Tarso Cabrini Jr. ${ }^{1}$
}

\begin{abstract}
RESUMO: Camilo Pessanha, nascido em Coimbra, Portugal, em 1867, viveu a maior parte de sua vida na colônia portuguesa de Macau, na China, lecionando, e exercendo cargos na área jurídica. Sua vida tem sido objeto das mais variadas controvérsias, causadas, tanto pela distância geográfica em que se encontrava, quanto pelos numerosos desafetos que teve de cultivar, durante sua vida. Os esforços empreendidos por estudiosos como Paulo Franchetti, da Unicamp/Brasil, e Daniel Pires, em Portugal, têm sido muito bem-sucedidos, no processo de "desmistificação" da imagem do poeta, pelo qual os exageros são polidos, e o "verdadeiro" se realça, daquilo que, de início, é "verossímil". Dentre as imagens que a crítica de viés biográfico procurou construir está a de um pensador e escritor xenófobo, que desprezava o país que o acolheu. Aderindo à tendência de "desmistificar" o poeta, embora, correndo o risco de "mistificá-lo" ao revés, procuramos, no presente artigo, dar uma interpretação a uma das mais curiosas fotografias que Camilo Pessanha nos deixou: a conhecida foto "da Praia da Chácara do Leitão", que, em nosso entender, é um testemunho tácito da dedicação que o poeta teve em relação à sua nova pátria: a China, culturalmente entendida, muito além da política, ou da geografia.
\end{abstract}

PALAVRAS-CHAVE: Camilo Pessanha (1867-1926); Fotografia; Taoismo; Macau; China.

\section{ON A PICTURE OF CAMILO PESSANHA}

ABSTRACT: Camilo Pessanha, born in Coimbra, Portugal, in 1867, lived the most of his life in China, the Portuguese colony of Macau, teaching and performing positions in the legal field. His life has been the subject of many controversies, caused by the geographical distance he was in, and caused, too, by the numerous enemies he had cultivated through his professional activities. Efforts made by scholars like Paulo Franchetti, from UNICAMP/Brazil, and Daniel Pires, in Portugal, have been successful in demystify the image of the poet, polishing that exaggerations, and highlighting what seems true from what is merely "likely". Among the "images" the criticism of biographical bias sought to build is that of a xenophobic thinker, who supposedly despised the country that hosted him. This article seeks to give an interpretation to a picture, one of the most curious that Pessanha left us, that is known as "the picture of the Praia da Chácara do Leitão", which, in our view, shows a veiled testimony of that love the poet dedicated to his new homeland: the cultural China.

KEYWORDS: Camilo Pessanha (1867-1926); Photography; Taoism; Macau; China.

\footnotetext{
${ }^{1}$ Professor Titular I de Português Instrumental na Faculdade de Direito OAPEC (Santa Cruz do Rio Pardo/SP).
} 
A fotografia que queremos focalizar é aquela chamada de "a foto da Praia do Leitão" ou "da Chácara do Leitão", referência a uma praia da Macau dos anos de 1920. Nessa fotografia, vemos o poeta, em "farrapos", acompanhado de seus dois cães - um deles, o "Arminho", figura notável, entre os estudantes do Liceu, onde Pessanha lecionava. Com uma bengala deixada em apoio sobre a perna, Pessanha senta-se a uma escadaria de pedras, e seu olhar é triunfante, sereno, calmo; sorri; seus sapatos são "à mendigo", e o pé direito "ostenta" uma curiosa sandália - que veremos, repetida, em outra instância, muitíssimo diferente, mas, do mesmo modo, "oriental".

Sabemos que o poeta é, ainda, um personagem controverso, na História Literária Portuguesa. Muitas lendas se fizeram, devido à sua vida longínqua, e essas lendas têm sido muito bem combatidas, ao longo do tempo, pelo professor Paulo Franchetti, da Unicamp/Brasil. Hoje, podemos ter um retrato mais exato de Camilo Pessanha, um homem que, mesmo sendo um exemplar heterodoxo da sociedade colonial portuguesa, nem por isso foi o lastimável espécime humano que a crítica de viés biográfico do século $\mathrm{XX}$ nos deixou, baseada, no mais das vezes, em relatos de desafetos que o poeta e jurista recolheu, em sua trajetória profissional.

Nascido em 1867, em Coimbra, Portugal, de um casamento jamais legitimado, Camilo Pessanha formou-se em Direito, pela Universidade de Coimbra, e, após sua formatura, começou a trabalhar na área jurídica, em comarcas provinciais, escrevendo pequenos textos e crônicas para jornais de sua cidade, ou de Mangualde, cidade em que seu dileto amigo, Alberto Osório de Castro, dirigia O Novo Tempo.

Em 1894, Pessanha segue para a China, a fim de lecionar Filosofia, no então recéminaugurado Liceu de Macau. Em suas cartas ao pai, datadas do mesmo ano, percebe-se que estava entusiasmado com essa aventura, como atestam estes post-scripta:

Ando a estudar com todo o interesse, apesar da minha surdez, a língua e os costumes chinas. Quando souber alguma coisa, poderei então escrever, e desde já prometo escrever uns artigos em que a minha pessoa não entre para nada. O que têm os leitores do jornal com a minha pessoa (?) (...) Quase já estou animado a escrever sobre coisas do Oriente. (Cartas de 08 e de 28 de maio, QUADROS, 1988, p. 80).

Esse entusiasmo juvenil, em espírito sensível, traduz-se, muitas vezes, em humor, como se vê nesta fotografia, datada de $1896^{2}$ :

\footnotetext{
${ }^{2}$ Constante em PIRES, 1992, p. 121.
} 


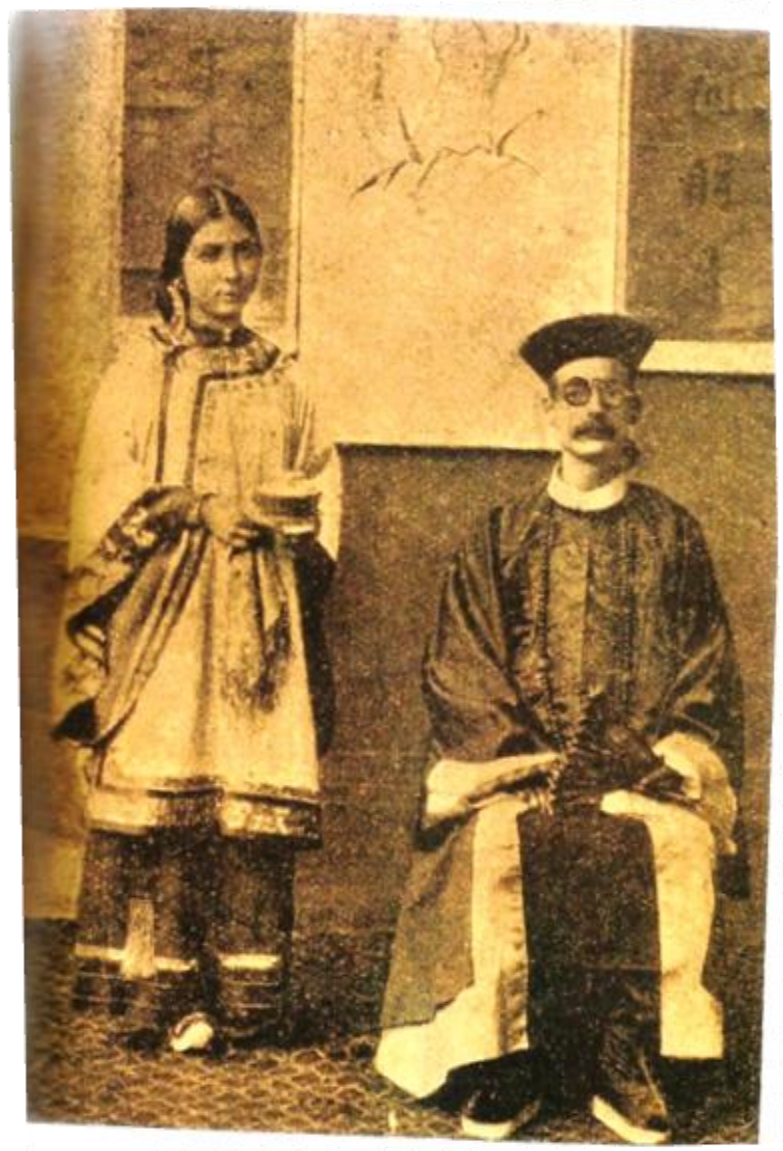

Em visita à sua Pátria, e em companhia de uma de suas irmãs, Camilo Pessanha aparece vestido de "mandarim chinês", em uma das numerosas mises-en-scène que costumava montar, para suas fotografias. A par de fotografias mais convencionais, muito abundantes, temos esses exemplos de um verdadeiro "teatro", muito bem montado, mas, que, também, podia ser improvisado, como se vê na fotografia seguinte ${ }^{3}$, tirada na casa que o poeta dividia com seu colega João Pereira Vasco, em Macau:

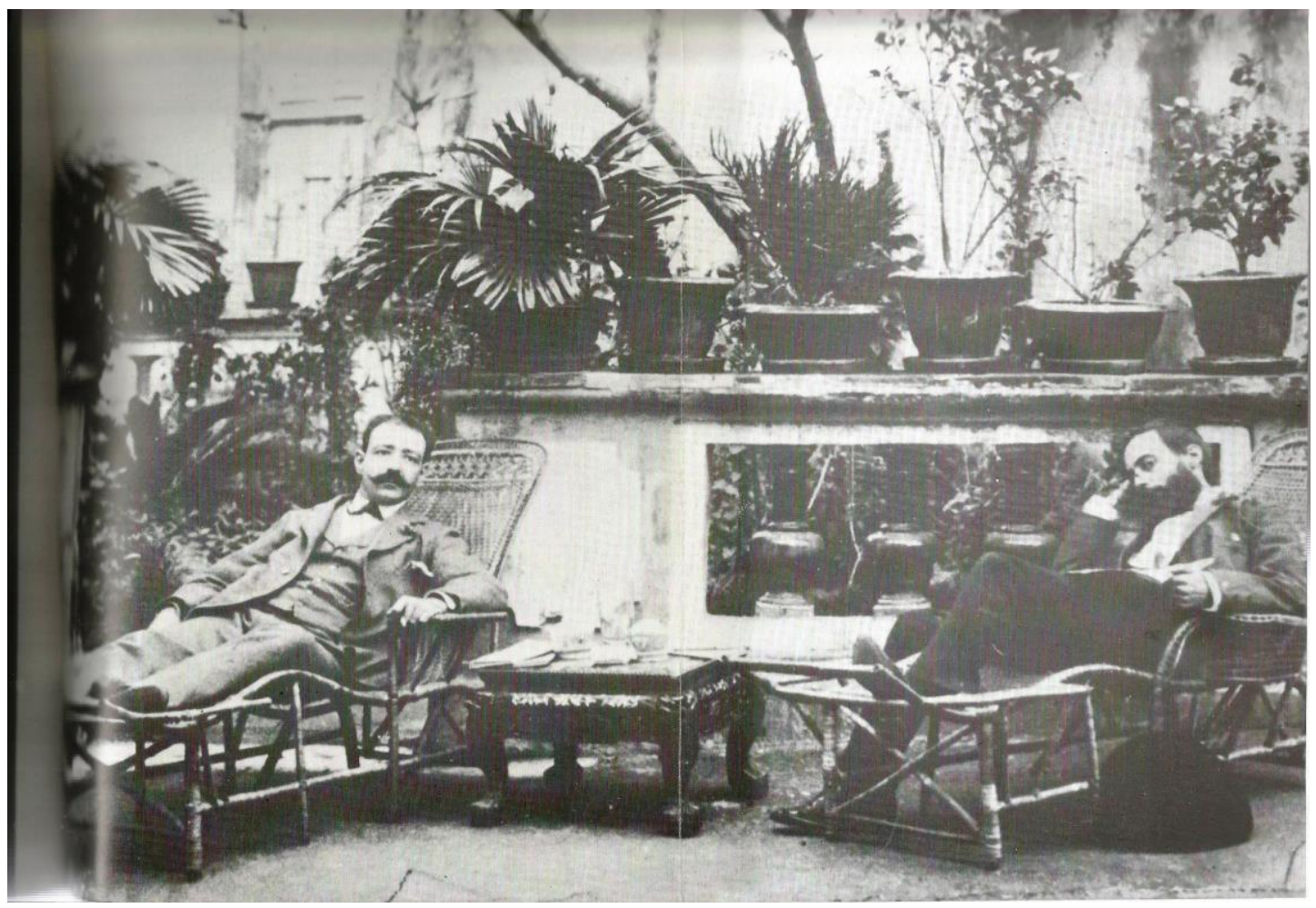

3 Também constante em PIRES, 1992, p. 111. 
Reparemos (se a reprodução nos permitir) que o semblante de Camilo Pessanha, à direita, tem um olhar "satânico", em tudo semelhante ao de um poète mandit, a que se soma uma pose não convencional, e uma atitude de estudante, ou de letrado, indisciplinado, que, uma vez "surpreendido" em pleno ato de leitura, ou de estudo, surpreende, por sua vez, o fotógrafo com o seu sarcasmo.

A fotografia em questão, ao que tudo indica, foi tirada na mesma ocasião em que esta outra ${ }^{4}$ :

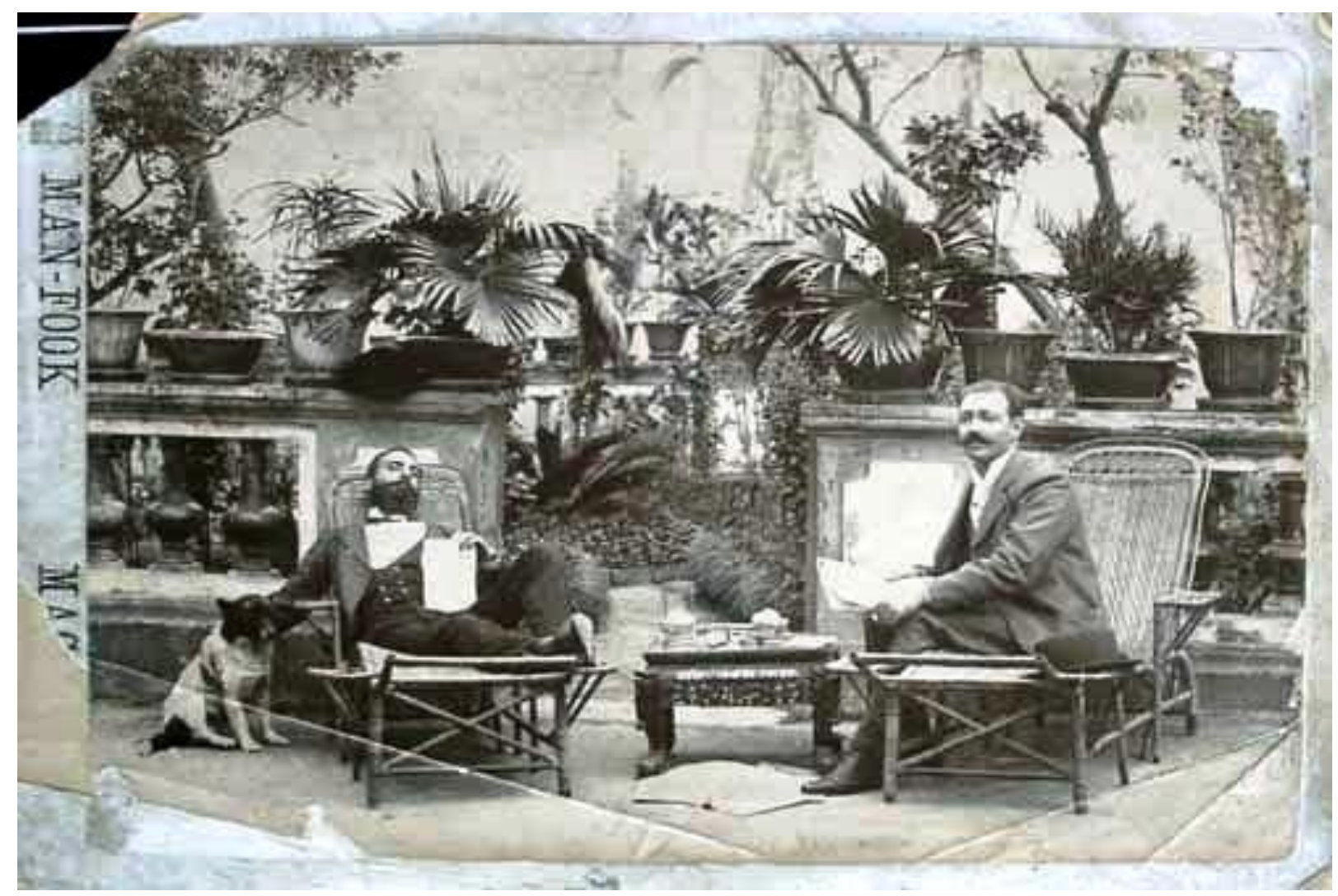

Vemos, mais uma vez, o personagem "surpreendido", em outra situação própria do poète maudit, mas, em circunstância muito diferente. Ao invés do sarcástico "satanista", "luciferino", temos o "desalentado", "afadigado ao extremo", "poeta ao fim da vida", ou "em pleno spleen", atingindo, já, as raias da morte, em plena juventude e vida. Desta vez, o "poeta maldito" "paga por seus pecados", e sofre do "mal de se viver". Ao seu lado, como fiel consolo, um cão - mas, não o famoso "Arminho", do Liceu de Macau.

Em ambas as fotos da casa de Macau, os retratos podem ser divididos ao meio, e teremos, assim, duas figuras muito distintas: de um lado, o professor João Pereira Vasco, inconfundível; e, do outro lado: um personagem.

\footnotetext{
${ }^{4}$ Disponível em: VIEGAS, Mario. "Conversa vadia sobre Camilo Pessanha" http://marioviegasparaquasetodos.blogspot.com.br/2013/04/conversa-vadia-sobre-camilopessanha.html.

(Acessado em: 27 de agosto de 2013).
} 
Nesse contexto de mises-en-scène fotográficas, encontramos esta outra "cena", conhecida como "a fotografia do Rio das Pérolas", atribuída ao ano de 1917 (PIRES, 1992, p. 5). Como veremos, a foto parece formar um "díptico" com aquela que nos propusemos estudar (a da "Praia do Leitão"). O cenário é o mesmo. Os acompanhantes, os mesmos; as mesmas roupas, e o aspecto. As diferenças, porém, são muito grandes, como veremos.

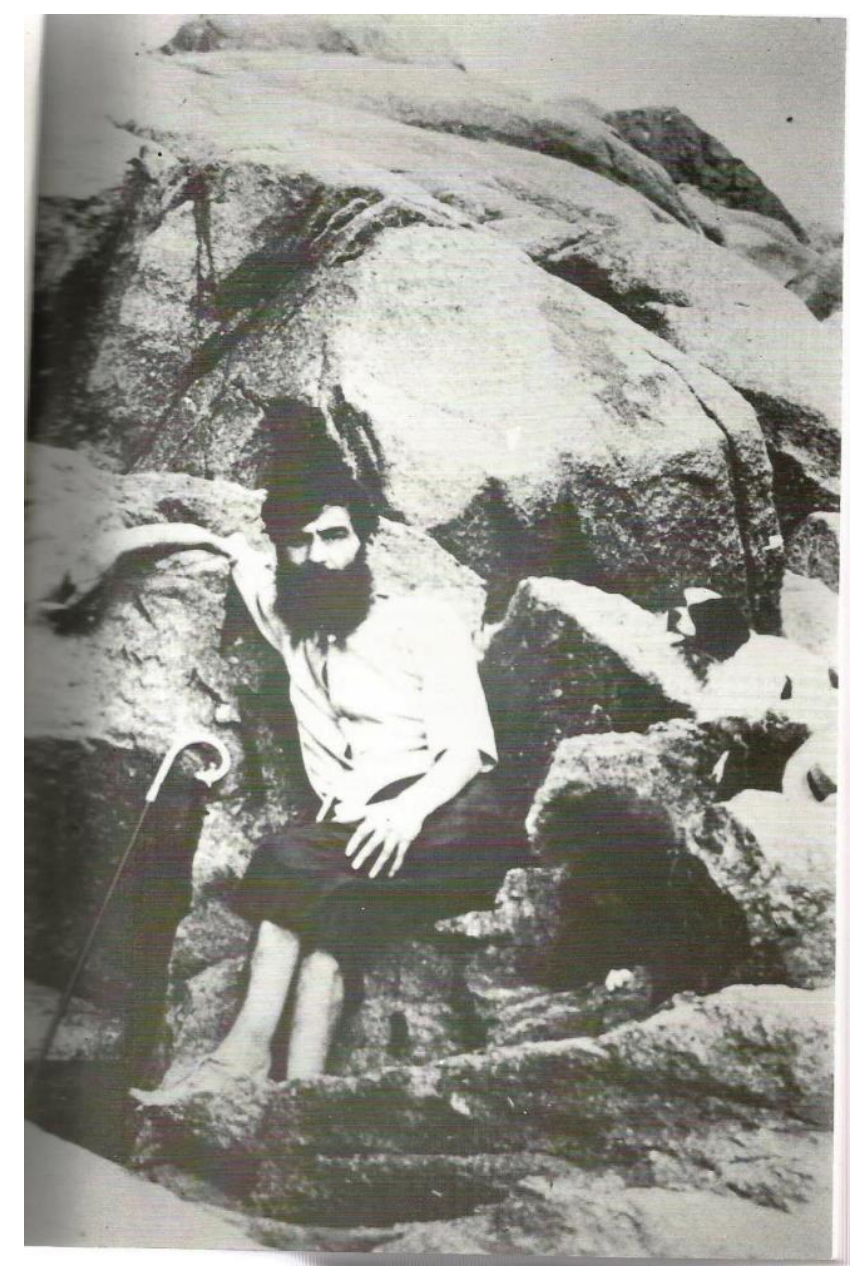

Aqui, Camilo Pessanha é uma espécie de "náufrago" da civilização, que guarda, ainda, alguns resquícios dessa civilização, como o cigarro, à mão direita, e a bengala, ao lado, apoiada nas pedras. Ao canto direito, temos o cão "Arminho", seu inseparável companheiro. O olhar do personagem é desafiador, altivo, em relação ao observador que o "surpreende" em pleno ato de descanso, em plena "selvageria" dos cabelos, das barbas e das roupas.

Vejamos, agora, a foto cujo estudo nos propomos: 


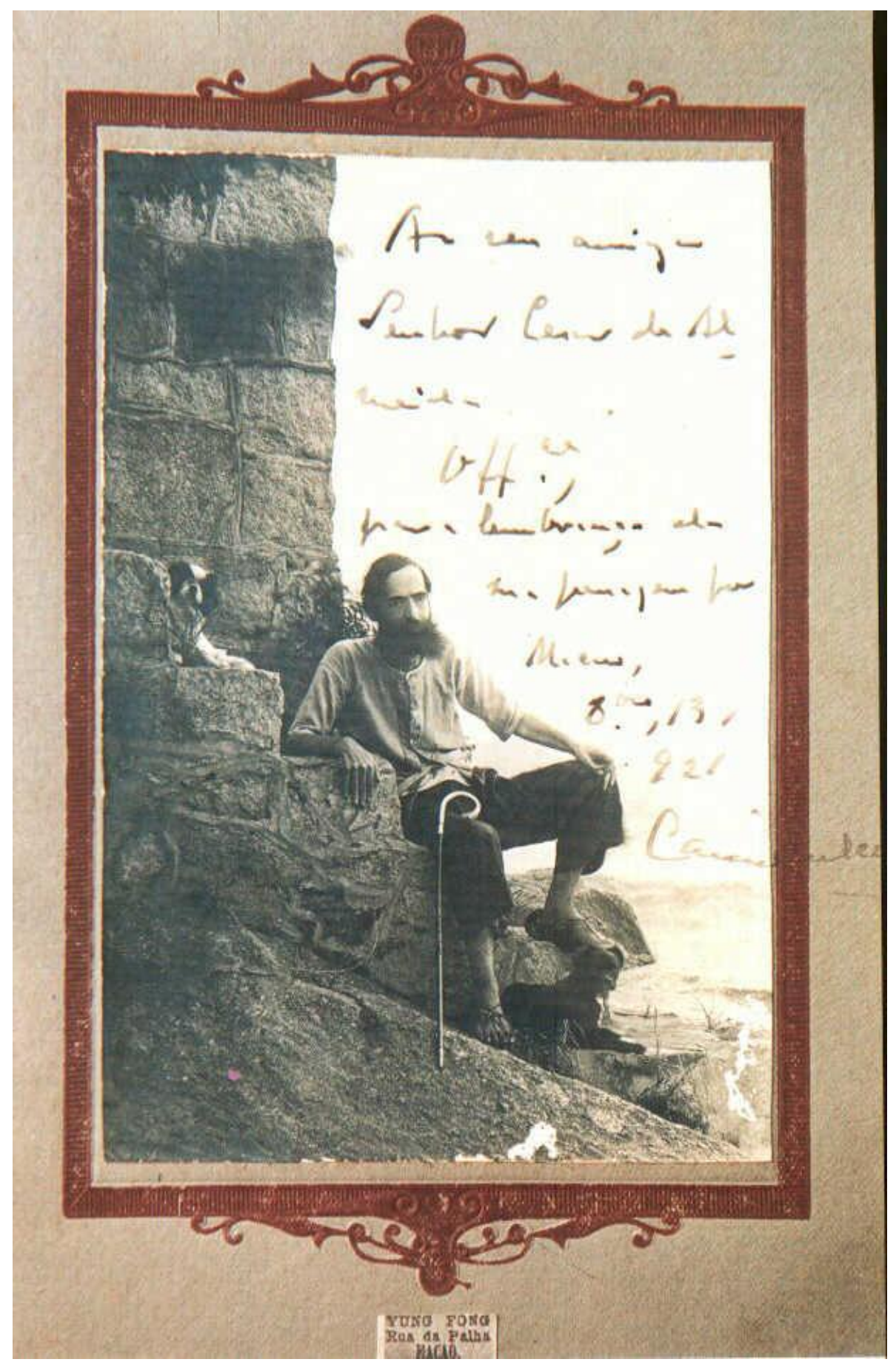

Trata-se, como se vê, do mesmo "náufrago", mas, com uma atitude e um olhar muito diversos: muito serenos e seguros. O retrato está datado de 1921, e é dedicado ao amigo César de Almeida. Queremos tecer algumas considerações acerca dessa imagem surpreendente e desconcertante, depois de termos demonstrado, suficientemente, como Camilo Pessanha montava, ou improvisava, as suas "cenas" fotográficas.

Queremos enfatizar, na "fotografia da Chácara do Leitão", um aspecto que, no mar de referências e de documentos sobre Camilo Pessanha, não foi, ainda, notado. Para explicá-lo, porém, é necessário se fazer uma breve volta no tempo, até o ano de 1916, 
quando o poeta doou, ao Estado português, sua volumosa coleção de arte chinesa, que havia adquirido, durante anos, nas casas de antiguidades de Macau.

A coleção de Pessanha era composta de estatuetas, exemplares de caligrafia, pinturas e artesanatos, em geral, e, hoje, encontra-se depositada no Museu Machado de Castro, em Coimbra. Entre as peças, consta do Catálogo, como “item 13" (cf. QUADROS, 1988, p. 191), a seguinte pintura ${ }^{5}$ de Sou-Lôc-Pang, ou Su Liupeng, artista que a teria pintado em 1851:

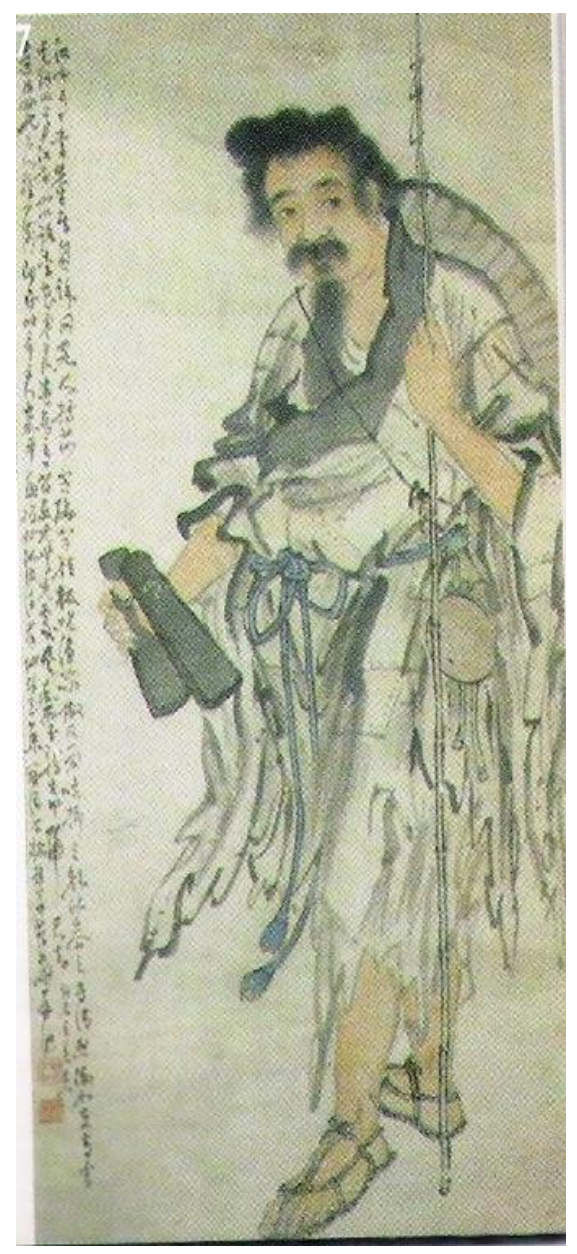

Trata-se do retrato de um personagem taoista, ou, de um "imortal", como se dizia, na época.

A coleção de Pessanha reunia vários destes personagens, muito populares, na cultura chinesa. Este personagem, porém, tem uma importância especial, para nós. Para além das roupas em desalinho, e do bordão de caminhante, reparamos em suas sandálias, e vemos que são as mesmas que Camilo Pessanha usa, em seu pé direito, na fotografia da "Chácara do Leitão":

\footnotetext{
${ }^{5}$ Reproduzida de RIBEIRO, "Camilo Pessanha colecionador de arte chinesa". Macau, v. 3, n. 2, p. 68-78, 2000.
} 

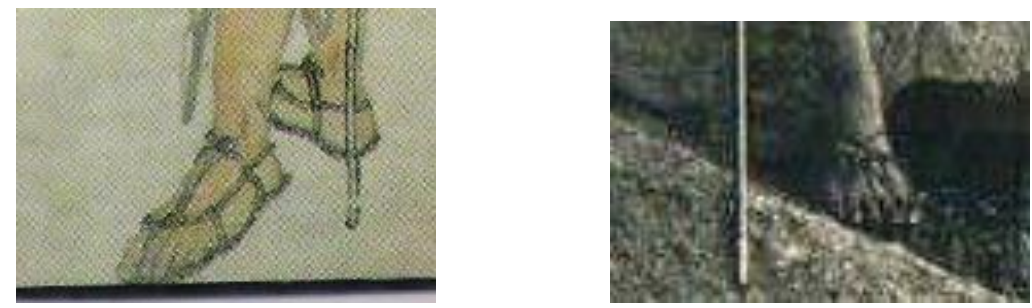

Teria, Camilo Pessanha, adotado a fantasia de "imortal taoista"?

É bem possível que sim, pois, conhecendo a cultura chinesa, como a conhecia, é perfeitamente admissível que tivesse adotado a "fantasia" que, na cultura europeia, encontra algum paralelo na "figura" do "Feliz Independente do Mundo e da Fortuna", título de um livro português do século XVIII, que, em termos pictóricos, encontra exemplo na conhecida pintura de Gustave Courbet (1819-1877), Bonjour, Monsieur Courbet, de 1854:

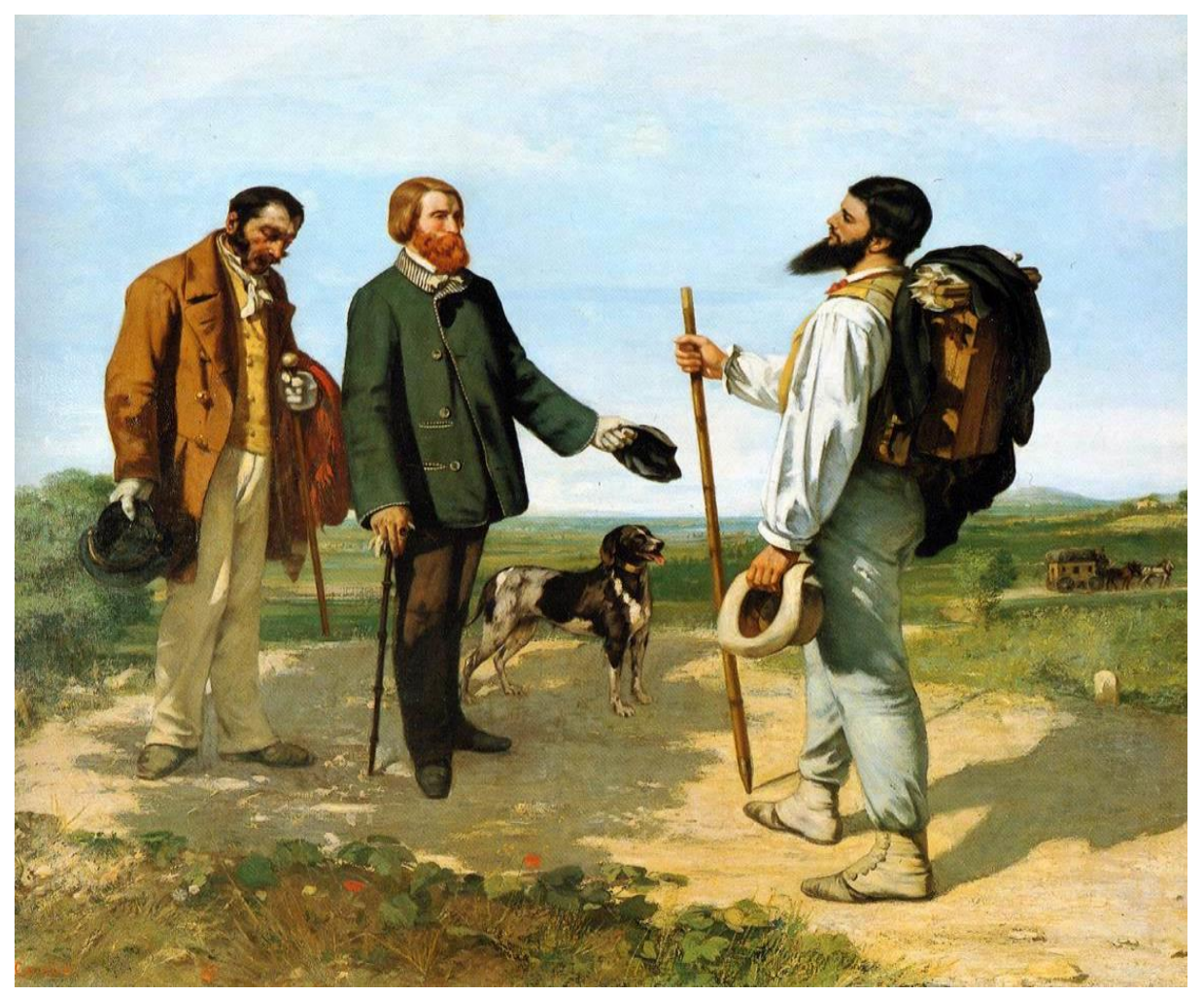

Uma sandália, talvez, não seja o suficiente para se provar que Camilo Pessanha, na Chácara do Leitão, fantasia-se de "imortal taoista". Entretanto, como pretender "provar" algo a respeito de uma imagem, quando, sobre ela, faltam palavras? Ainda assim, levando-se em consideração o fato de Pessanha ter sido o dono de uma pintura que, nos pés, reproduzia o mesmo objeto, esse detalhe pode, perfeitamente, ser intencional.

As ligações de Camilo Pessanha com a cultura chinesa são fartamente provadas. É, de fato, cansativo, para o leitor familiarizado com Pessanha, repassar todas as informações a respeito. Suas ligações com o Taoismo, doutrina iniciada por Lao-Tzu, no século VI a. C. (ele próprio, também, um "imortal” semilendário) são decorrentes dessa sua ligação maior 
com a cultura chinesa, uma vez que o Taoismo é uma doutrina entranhada no pensamento chinês, assim como o Confucionismo.

A distinção entre Confucionismo e Taoismo, talvez, no momento, seja desnecessária, mas, no caso de nosso leitor ser menos familiarizado com a cultura chinesa, basta distinguir o Confucionismo como uma doutrina moral e o Taoismo como uma doutrina mística. Isso poderá enraivecer os mais detalhistas, mas, pode ser o suficiente para os leitores menos exigentes.

Esta é, portanto, nossa interpretação da fotografia da "Chácara do Leitão": Camilo Pessanha, "fantasiado" de "sábio taoista", de "feliz independente do mundo e da fortuna", o que, no fundo, é o mesmo, e Pessanha sabia disso: que toda doutrina de "sabedoria" é a mesma, independente das línguas, raças, e civilizações.

Mas, uma "sandália", de cordas, em tudo semelhante à de um retrato que ele mesmo colecionara, depõe a favor do Oriente, em nossa interpretação, contribuindo para a construção da imagem de Camilo Pessanha como sinófilo, e contribuindo para a superação de um viés crítico, muito forte, na fortuna crítica de Pessanha, que é o viés "nacionalista", instigado, principalmente, por João de Castro Osório (1899-1970), filho de Ana de Castro Osório, dileta amiga do poeta, e responsável pela primeira edição da Clepsydra (1920), e que se esforçou por "limpar", da biografia de Camilo Pessanha, todo traço de sinofilia.

\section{BIBLIOGRAFIA}

GONÇALVES, Adelto. "Camilo Pessanha: retrato por inteiro". Disponível em: http://www.storm-magazine.com/novodb/arqmais.php?id=544\&sec=\&secn $=. \quad$ Acesso em: 27 de agosto de 2013.

PIRES, Daniel. Camilo Pessanha, prosador e tradutor. Macau: Instituto Português do Oriente/Instituto Cultural de Macau, 1992.

QUADROS, Antonio. Camilo Pessanha, Contos, crônicas, cartas e textos de temática chinesa. Sintra (Portugal) : Europa-América, 1988.

RIBEIRO, José D. "Camilo Pessanha colecionador de arte chinesa". Macau, v. 3, n. 2, p. 68-78, 2000.

VIEGAS, Mario. "Conversa vadia sobre Camilo Pessanha". Disponível em: http://marioviegasparaquasetodos.blogspot.com.br/2013/04/conversa-vadia-sobrecamilo-pessanha.html. Acesso em: 27 de agosto de 2013. 